\title{
Enriched environment and masticatory activity rehabilitation recover spatial memory decline in aged mice
}

Fabíola de Carvalho Chaves de Siqueira Mendes ${ }^{1}$, Marina Negrão Frota de Almeida', André Pinheiro Gurgel Felício ${ }^{1}$, Ana Carla Fadel', Diego de Jesus Silva', Thaíssa Gomes Borralho', Rodrigo Perez da Silva', João Bento-Torres' ${ }^{1}$ Pedro Fernando da Costa Vasconcelos ${ }^{2}$, Victor Hugh Perry ${ }^{3}$, Edson Marcos Leal Soares Ramos ${ }^{4}$, Cristovam Wanderley Picanço-Diniz ${ }^{1}$ and Marcia Consentino Kronka Sosthenes ${ }^{1 *}$

\begin{abstract}
Background: To measure the impact of masticatory reduction on learning and memory, previous studies have produced experimental masticatory reduction by modified diet or molar removal. Here we induced spatial learning impairment in mice by reducing masticatory activity and then tested the effect of a combination of environmental enrichment and masticatory rehabilitation in recovering spatial learning at adulthood and in later life. For 6 months $(6 \mathrm{M})$ or 18 months $(18 \mathrm{M})$, we fed three groups of mice from postnatal day 21 respectively with a hard diet (HD) of pellets; pellets followed by a powdered, soft diet (HD/SD, divided into equal periods); or pellets followed by powder, followed by pellets again (HD/SD/HD, divided into equal periods). To mimic sedentary or active lifestyles, half of the animals from each group were raised from weaning in standard cages (impoverished environment; IE) and the other half in enriched cages (enriched environment; EE). To evaluate spatial learning, we used the Morris water maze.
\end{abstract}

Results: IE6M-HD/SD mice showed lower learning rates compared with control (IE6M-HD) or masticatory rehabilitated (IE6MHD/SD/HD) animals. Similarly, EE-HD/SD mice independent of age showed lower performance than controls (EE-HD) or rehabilitated mice (EE-HD/SD/HD). However, combined rehabilitation and EE in aged mice improved learning rate up to control levels. Learning rates did not correlate with swim speed.

Conclusions: Reduction in masticatory activity imposed on mice previously fed a hard diet (HD/SD) impaired spatial learning in the Morris water maze. In adults, masticatory rehabilitation recovered spatial abilities in both sedentary and active mice, and rehabilitation of masticatory activity combined with EE recovered these losses in aged mice.

Keywords: Mastication, Enriched environment, Masticatory rehabilitation, Spatial learning, Morris water maze

\footnotetext{
* Correspondence: makronka@gmail.com

'Universidade Federal do Pará/UFPA, Instituto de Ciências Biológicas,

Laboratório de Investigações em Neurodegeneração e Infecção, Hospital

Universitário João de Barros Barreto, Rua dos Mundurucus, 4487 - Guamá

Belém, Pará, Brasil

Full list of author information is available at the end of the article
} 


\section{Background}

The proportion of the elderly population that experiences dementia is rapidly increasing, and both human and animal studies have indicated a relationship between reduced masticatory function (e.g., from occlusal disharmony) in elderly individuals and cognitive impairment $[1,2]$. In addition, data from human and animal reports reveal that an impoverished environment (IE) is associated with aggravation of aging-related cognitive decline; for a recent review see [3]. Indeed, compared with geriatric persons with poor levels of physical and social activities, exercise programs for institutionalized older people improve cognitive function [4-6]. Consistent experimental data from aged mice and rats maintained in IEs also point to spatial memory impairments in Morris water maze tests $[7,8]$. Water maze tests require acquisition and retrieval of spatial information [9], and this hippocampal-dependent task $[10,11]$ can be impaired by a variety of structural/functional changes including aging [12], IE [3], and occlusal disharmony [2,13].

Human epidemiological studies [14-16] and experimental data from rodents [17-19] also show direct correlations between aging, masticatory imbalances (e.g., occlusal disharmony), and cognitive decline, but with no references to environmental conditions. Experimental approaches imposing masticatory deprivation, like tooth-loss [20], long-term soft diet [21], or bite-rise occlusion, suggest a behavioural displacement, but more research is needed into the effects of rehabilitation. Here we examined outcomes at the intersection of masticatory deprivation, environmental conditions, and spatial memory impairments in adult (6-month-old; 6M) and aged (18-monthold; 18M) mice. To assess the effects of masticatory rehabilitation on the Morris water maze task, we used different sequences of hard diet (HD) and soft diet (SD) on the aged and young mice and included an environmental component with an IE or enriched environment (EE). To mimic masticatory rehabilitation, we fed some animals with HD followed by SD, with a return to HD, and compared them to animals without rehabilitation (HD/SD).

\section{Results}

Masticatory reduction, environmental changes, and water maze tests at 6 and 18 months.

\section{Learning rate}

Figure 1 depicts the diet regime, age, and environmental influences on learning rate of the best five performances of each experimental group on the fourth training day. The top panel (Figure 1A) indicates the significant betweengroup differences in the learning rates, and the bottom (Figure 1B) panel shows individual performances and group means. Note that at $6 \mathrm{M}$, impoverished conditions associated with a reduction in masticatory activity (HD/ $\mathrm{SD})$ were also associated with lower learning rate values compared with control (HD) or masticatory rehabilitated (HD/SD/HD) mice. On the other hand, spatial learning performance was impaired in aged IE mice regardless of diet regime but less so in the rehabilitated group. Similarly, EE-HD/SD animals independent of age showed lower performance than EE controls (HD) or rehabilitated mice (EE-HD/SD/HD). However, rehabilitation $+\mathrm{EE}$ in aged mice improved learning rates up to EE control levels. Indeed, on the fourth training day, learning rate was influenced by diet regime $\left(\mathrm{F}_{(2,48)}=21.2\right.$, $\mathrm{p}<$ $0.000001)$ and age $\left(\mathrm{F}_{(1,48)}=13.6, \mathrm{p}<0.000567\right)$ with interactions between environment and age $\left(\mathrm{F}_{(1,48)}=\right.$ 16.7, $\mathrm{p}<0.00164$ ). Pairwise comparisons (Tukey Honestly Significant Difference) showed significant differences between mean values of IE6M-HD (90.19 \pm 2.74 , mean \pm S.E.) and IE6M-HD/SD (51.60 \pm 5.40$)(\mathrm{t}(8)=$ 6.38, $\mathrm{p}<0.0002) ;$ IE6M-HD and IE6M-HD/SD/HD $(78.49 \pm 4.43)(\mathrm{t}(8)=2.25, \mathrm{p}<0.05) ;$ IE6M-HD and IE18M-HD (51.02 \pm 7.26$)(\mathrm{t}(8)=5.05, \mathrm{p}<0.001)$; IE6M$\mathrm{HD}$ and EE6M-HD $(76.14 \pm 2.48)(\mathrm{t}(8)=3.80, \mathrm{p}<$ 0.005); IE6M-HD/SD and IE6M-HD/SD/HD (t $(8)=$ 3.85, $\mathrm{p}<0.005)$; IE6M-HD/SD/HD and IE18M-HD/SD/ $\mathrm{HD}(44.25 \pm 9.89)(\mathrm{t}(8)=3.16, \mathrm{p}<0.013)$; and IE18M$\mathrm{HD} / \mathrm{SD} / \mathrm{HD}$ and EE18M-HD/SD/HD (79.75 \pm 4.77) $(\mathrm{t}(8)=3.23, \mathrm{p}<0.01)$. For EE-only animals, we identified the following values: EE6M-HD and EE6M-HD/ $\mathrm{SD}(45.91 \pm 8.53)(\mathrm{t}(8)=3.40, \mathrm{p}<0.009) ; \mathrm{EE} 6 \mathrm{M}-\mathrm{HD} / \mathrm{SD}$ and EE6M-HD/SD/HD (70.66 \pm 3.19$)(\mathrm{t}(8)=2.72, \mathrm{p}<$ 0.03); EE18M-HD (73.03 \pm 8.22) and EE18M-HD/SD $(44.35 \pm 5.70)(\mathrm{t}(8)=2.87, \mathrm{p}<0.02)$; and EE18M-HD/SD and EE18M-HD/SD/HD $(\mathrm{t}(8)=4.76, \mathrm{p}<0.001)$.

\section{Swim speed and distance travelled}

Because a reduction in escape latency during training might simply suggest that mice learned to swim faster across days and or abandoned the thigmotactic strategy that is preferred during the very first days of training, in Figure 2 we show total distance travelled (path length) (Figure 2A) and respective mean trajectories (Figure 2B); distance travelled on the quadrant opposite the platform (Figure 2C); and the average swim speed (Figure 2D). Three-way ANOVA of these data revealed that distance travelled was influenced by age $\left(\mathrm{F}_{(1,48)}=13.6, \mathrm{p}<0.0006\right)$ and diet $\left(\mathrm{F}_{(2,48)}=7.55, \mathrm{p}<0.001\right)$ with significant interaction between environment and age $\left(\mathrm{F}_{(1,48)}=7.40, \mathrm{p}<\right.$ 0.009). As expected, the best performances in learning rates were associated with shorter distances travelled. Indeed, pairwise comparisons showed that IE6M-HD/SD $(241.36 \pm 23.77 \mathrm{~cm}$, mean \pm S.E. $)$ travelled longer distances than IE6M-HD $(116.23 \pm 16.07)(\mathrm{t}(8)=4.36, \mathrm{p}<$ $0.002)$ and IE6M-HD/SD/HD $(98.03 \pm 19.55)(\mathrm{t}(8)=4.66$, $\mathrm{p}<0.002)$, but shorter than IE18M-HD/SD (467.93 \pm 

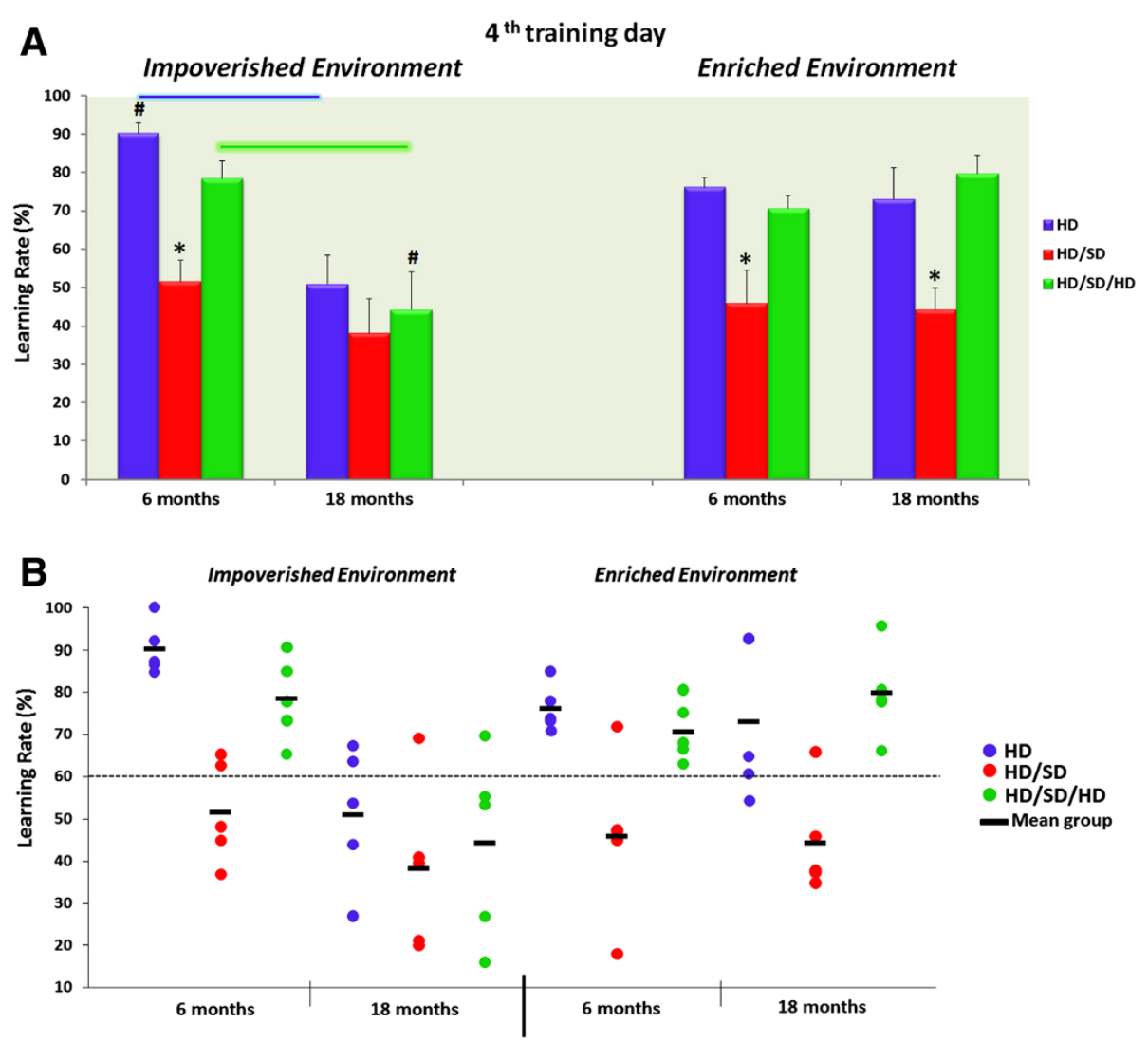

Figure 1 Learning rate on water maze test under different diet regimes, ages, and environments. Graphic representation of diet regime, age, and environmental influences on learning rate of the best five performances of each experimental group on the fourth training day. In the top panel $(\mathbf{A})$, indicated in different colours, are the mean values and standard errors of the learning rates with respective significance values, and in the bottom panel (B) are the individual performances (coloured, solid circles) and mean groups (dark dashes between solid circles). $\left(^{*}\right)$ indicates significant differences in learning rates between different diet regimes, (\#) significant differences in learning rates between environments, and coloured line connectors differences in learning rates between age.

79.75) $(\mathrm{t}(8)=2.72, \mathrm{p}<0.026)$ and IE18M-HD/SD/HD $(281.14 \pm 63.03)(\mathrm{t}(8)=2.78, \mathrm{p}<0.02)$. Consistent with learning rate results, IE6M-HD also travelled shorter distances than EE6M-HD $(179.87 \pm 21.43)(\mathrm{t}(8)=2.38, \mathrm{p}<$ 0.045). In addition, EE18M-HD/SD (360.23 \pm 13.21$)$ swam longer distances to find the platform than EE18M-HD $(183.82 \pm 52.02)(\mathrm{t}(8)=3.29, \mathrm{p}<0.01)$ or $\mathrm{EE} 18 \mathrm{M}-\mathrm{HD} / \mathrm{SD} /$ HD $(207.83 \pm 26.32)(\mathrm{t}(8)=5.18, \mathrm{p}<0.0008)$.

In keeping with these findings, the distance travelled in the opposite quadrant to the platform was also influenced by age $\left(\mathrm{F}_{(1,48)}=10.9, \mathrm{p}<0.0019\right)$ and diet $\left(\mathrm{F}_{(2,48)}=4.83, \mathrm{p}<0.01\right)$, but no interactions were identified. Pairwise analysis demonstrated that IE6M-HD (19.69 \pm 6.54 , mean \pm S.E. $)$ swam less in the opposite quadrant than IE6M-HD/SD $(71.67 \pm 19.30)(\mathrm{t}(8)=2.55$, $\mathrm{p}<0.03)$ and IE18M-HD $(101.45 \pm 34.03)(\mathrm{t}(8)=2.36$, $\mathrm{p}<0.046)$. In addition, EE18M-HD/SD (109.78 \pm 14.11$)$ swam longer distances in the opposite quadrant than EE18M-HD $(51.69 \pm 14.62)(\mathrm{t}(8)=2.86, \mathrm{p}<0.02)$ and $\mathrm{EE} 18 \mathrm{M}-\mathrm{HD} / \mathrm{SD} / \mathrm{HD}(66.19 \pm 13.03)(\mathrm{t}(8)=2.27, \mathrm{p}<$ $0.05)$.
Finally, three-way ANOVA indicated that swim speed was affected by age $\left(\mathrm{F}_{(1,48)}=9.08, \mathrm{p}<0.004\right)$ and diet $\left(\mathrm{F}_{(2,48)}=9.26, \mathrm{p}<0.0004\right)$ with significant interaction between environment and age $\left(\mathrm{F}_{(1,48)}=5.51, \mathrm{p}<0.023\right)$. However, pairwise comparisons showed that IE6M-HD/SD $(9.67 \pm 0.63 \mathrm{~cm} / \mathrm{s}$, mean \pm S.E. $)$ swam faster than IE6M$\mathrm{HD}(7.35 \pm 0.78)(\mathrm{t}(8)=2.31, \mathrm{p}<0.05)$ and IE6M-HD/SD/ HD $(6.39 \pm 0.75)(\mathrm{t}(8)=3.33, \mathrm{p}<0.01)$ but slower than IE18M-HD/SD $(13.09 \pm 1.13)(\mathrm{t}(8)=2.63, \mathrm{p}<0.03)$. In addition, IE6M-HD/SD/HD swam slower than IE18M$\mathrm{HD} / \mathrm{SD} / \mathrm{HD}(9.05 \pm 0.83)(\mathrm{t}(8)=2.39, \mathrm{p}<0.04)$, and IE18M-HD/SD swam faster than IE18M-HD/SD/HD $(\mathrm{t}(8)=2.87, \mathrm{p}<0.021)$. However, swim speed did not change in animals raised in enriched conditions with a single exception: EE18M-HD (7.36 \pm 0.79$)$ swam slower than EE18M-HD/SD $(10.77 \pm 0.78)(\mathrm{t}(8)=3.07, \mathrm{p}<0.02)$.

Taking these results together, learning rates seem to be directly related to distance travelled, but swim speed values do not, suggesting that the behavioural effects are not the result of sensorimotor changes and that masticatory activity seems to affect spatial learning in the 


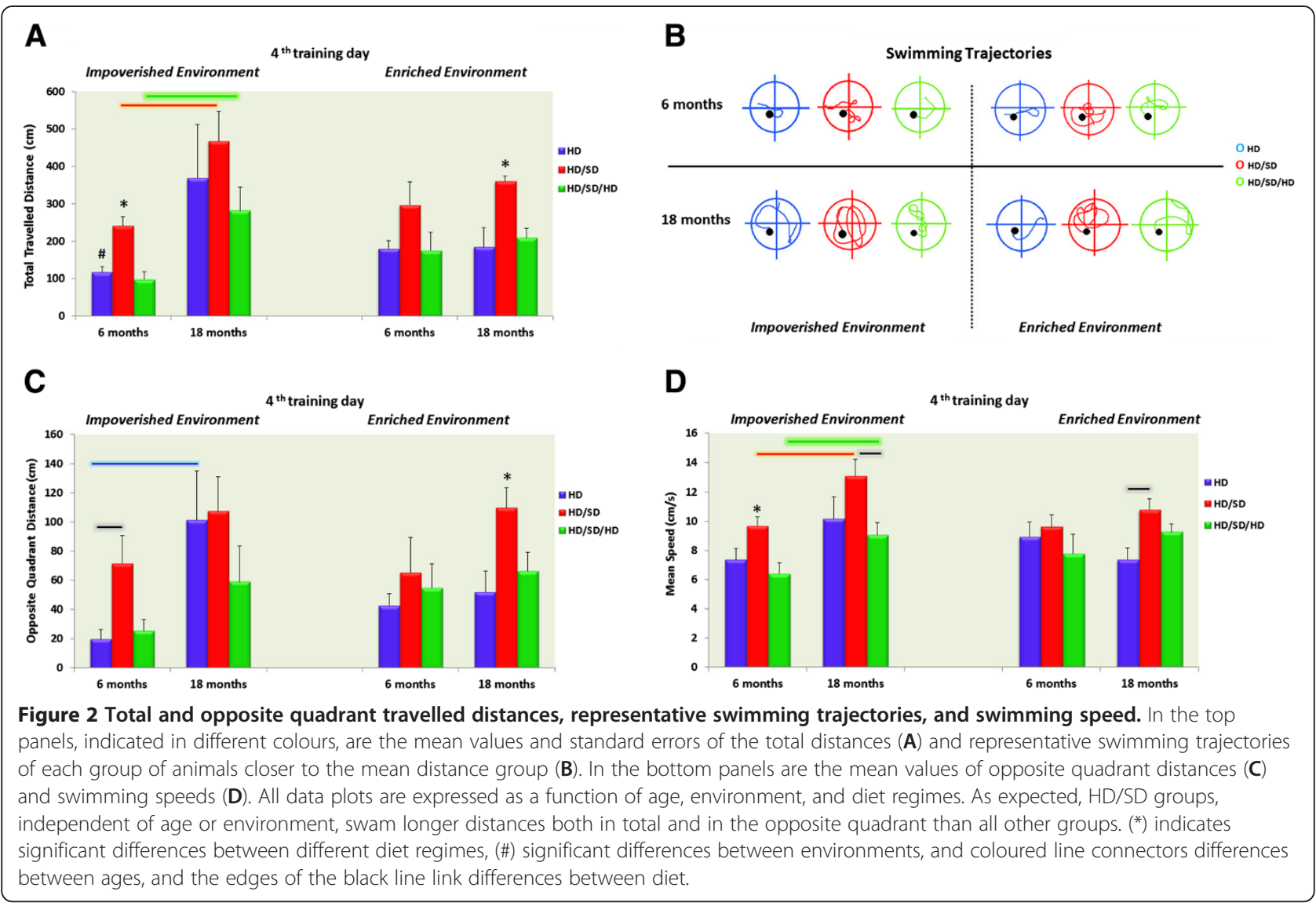

Morris water maze test. The findings also indicate that a combination of increased masticatory activity and EE in animals with a previous reduction in masticatory activity may benefit both young and aged mice.

\section{Body weight and diet regimes}

To detect a possible influence of diet regimes and environment on body weight, we weighed all animals after behavioural tests. One-way ANOVA revealed significant influence of diet regimes on body weight of IE animals $\left(\mathrm{F}_{(2,12)}=16.04, \mathrm{p}<0.0006\right)$, and IE6M-HD/SD $(52.84 \pm$ $2.45 \mathrm{~g}$, mean \pm S.E.) weighed significantly less than IE6MHD $(75.96 \pm 3.69)$ or IE6M-HD/SD/HD $(71.56 \pm 2.93)$ mice (Bonferroni post-tests, $\mathrm{p}<0.05$ ). No body weight differences were detected in EE animals. We did find a single significant inverse correlation between body weights and performance in the water maze in IE6M-HD/SD mice (Pearson's coefficient $=-0.99 ; \mathrm{R}^{2}=0.99, \mathrm{p}=0.0007$ ).

In addition, t-tests revealed no significant differences between body weights of IE6M-HD/SD and EE6M-HD/SD mice (two-tailed t-test, $\mathrm{p}=0.38$ ) and no differences in learning rates. Based on this finding, we speculated that the sedentary IE lifestyle is associated with being overweight and that the $\mathrm{HD} / \mathrm{SD}$ diet regime in IE may reduce food intake. Observing the active lifestyle of EE animals (EE6M-HD vs IE6M-HD, two-tailed t-test, $\mathrm{p}=0.0002$; EE6M-HD/SD/HD vs IE6M-HD/SD/HD, two-tailed t-test, $\mathrm{p}=0.0049$ ), we noted that it reduced weight gain independent of the diet regime. However, these differences disappeared after $18 \mathrm{M}$ in all diet regimes.

\section{Discussion}

In the present report, we tested the hypothesis that a combination of masticatory rehabilitation and EE would recover impaired spatial learning induced by a combination of IE and reduced masticatory activity. To mimic sedentary or active lifestyles, respectively, we raised mice from weaning onwards in either IE or EE. To mimic a reduction in masticatory activity, we fed a soft diet to mice previously fed with a hard diet (HD/SD) and compared water maze performances of this group with two other groups fed with continuous hard diet (HD - control group) or with a sequence of hard, soft, and hard diets (HD/SD/HD - rehabilitated group). We found that a reduction in masticatory activity and IE impaired spatial learning on the Morris water maze and a combination of masticatory rehabilitation and EE recovered spatial learning abilities of both adult and aged mice. 


\section{Aging cognitive decline and environment}

We tested adult and aged mice raised in IE or EE for spatial memory and learning using the water maze paradigm. The results revealed that all IE and EE adult mice could learn and remember the position of the hidden platform after four training days; however, only aged EE mice met the criterion of $60 \%$ or more in learning rate $(\mathrm{EE} 18 \mathrm{M}-\mathrm{HD}=73.03 \pm 8.22)$. Indeed, the aged IE mice learning rate was on average near the chance level $(\mathrm{IE} 18 \mathrm{M}-\mathrm{HD}=51.02 \pm 7.26)$. These findings suggest that after 6 months of impoverished conditions, the hippocampal requirements for spatial learning were spared in young mice and could be activated after training. As expected, memory capabilities became worse when advanced age was combined with IE; under these conditions, age-related spatial learning decline was aggravated. In contrast, EE-raised aged mice exhibited relatively unimpaired spatial learning in water maze tests, suggesting that the consolidation and retrieval mechanisms for these memories were spared under enriched conditions. These observations replicate previous results of ours and others in mice and rats undergoing spatial learning and memory tests [7,22-29].

More recently, we investigated the impact of institutionalization on aged humans, living sedentarily under poor conditions of cognitive and motor-sensory stimulation (impoverished-like conditions). Participants underwent neuropsychological tests, and outcomes were compared to those of an aged control group living in the community with their families (enriched-like conditions). Our findings revealed significantly higher scores among community-living participants. Consistent with this finding, institutionalized patients after 6 months of motor-sensory and cognitive stimulation (enriched-like environment) experienced significant improvement in their performances on neuropsychological tests [30].

\section{Rehabilitation of masticatory function to prevent adult and aging-related spatial learning losses}

A number of studies using a variety of behavioural assays, including the Morris water maze [18,19,31-36], passive avoidance [37], and radial arm maze [20,38,39], indicate that long-term soft-diet feeding or extraction of molar teeth results in learning and memory deficits [40]. Recent studies with the Morris water maze demonstrated that mice fed a hard diet required significantly less time to reach the platform than experimental mice and spent significantly more time in the former platform area, suggesting that hard-diet feeding is associated with improved spatial memory [41]. In addition, one-year-old [35] or 18-month-old [36] adult mice fed with a soft diet, compared to a solid-diet group, showed lower spatial performances on the Morris water maze. Similarly, SAMR1 and SAMP8 mice fed a solid diet performed better in the eight-arm radial maze than mice fed a powdered diet [39]. SAMP8 mice reach adult maturity at 6 months of age when learning and memory deficits become apparent in a variety of behavioural tests [42-45] and when reduced masticatory activity accelerates age-related learning and memory decline [40]. Occlusal disharmony also aggravates age-dependent deficits in spatial learning in the Morris water maze [17,46-49]; see [13,40] for recent reviews. Moreover, monkey studies demonstrate that when occlusal disharmony is removed, the associated stressful response disappears [50].

Here the results add a new piece of information, demonstrating a vigorous effect of diet changes on spatial learning in the Morris water maze after a reduction in masticatory activity imposed with a soft diet on mice previously fed a hard diet. We also demonstrated that these spatial learning losses can be promptly recovered by masticatory rehabilitation at adulthood (6M) but that aged mice (18M) require a combination of environmental stimuli and masticatory rehabilitation to obtain similar effects. Because the Morris water maze is a hippocampaldependent task, we suggest that rehabilitation of masticatory activity in adult mice and a combination of EE and masticatory rehabilitation in aged mice may rescue hippocampal function.

We emphasize that the animals were deprived of their masticatory activity but not fully suppressed in an effort to simulate the human condition. Taking all of the results together, we can speculate that oral rehabilitation and sensory-motor and cognitive stimulation may help protect human subjects from age-related cognitive decline and that these interventions would be more effective if implemented as early as possible.

\section{Conclusions}

An imposed reduction in masticatory activity by administration of a soft diet to sedentary mice previously fed a hard diet impaired spatial learning in the Morris water maze. The rehabilitation of masticatory activity of these deprived mice at adulthood, independent of environment, recovered spatial learning losses, and a combination of enriched environment and rehabilitation benefited significantly both young and aged mice. We are now investigating the cellular and molecular changes associated with spatial learning recovery after masticatory rehabilitation.

\section{Methods}

All animals, female albino Swiss mice, were maintained in accordance with the guidelines published by the $\mathrm{Na}$ tional Institutes of Health (Guide for the Care and Use of Laboratory Animals). The experimental protocol was tested and approved prior to study initiation by the Ethics Committee on Experimental Animal Research (from 
the Institute of Biological Sciences, Federal University of Pará, Brazil, CEPAE-UFPA:BIO004-09).

Environment, age, diet regimes, and experimental groups The EE consisted of two-level wire cages $(100 \times 50 \times 100$ $\mathrm{cm}$ ) equipped with ropes, rod bridges, tunnels, running wheels, and toys. Toys were made of different forms of plastic, wood, and metal of different colours and were changed periodically. Each EE cage housed 20 young and aged mice. Water and food were delivered to the top and bottom levels, respectively. This arrangement obliged mice to move from one compartment to another to drink and eat. Impoverished conditions comprised plastic cages $(32 \times 45 \times 16.5 \mathrm{~cm})$ without equipment or toys and covered by metal grids. The IE mice were maintained in groups of six until sacrifice. Each IE cage housed 9 young or aged mice. Animals had free access to food and water and were raised at a controlled room temperature $\left(23 \pm 1^{\circ} \mathrm{C}\right)$ and 12-hour light-dark cycle. Figure 3 depicts the experimental timeline.
All animals from IE or EE cages were organized into six groups according to diet regime (HD, $\mathrm{HD} / \mathrm{SD}$, or $\mathrm{HD} / \mathrm{SD} / \mathrm{HD}$ ) and age (6 or 18 months). Animals were housed either in enriched or impoverished environments from postnatal day 21 onwards, under one of the following diet regimes: IE6M (HD, $\mathrm{n}=28 ; \mathrm{HD} / \mathrm{SD}, \mathrm{n}=15 ; \mathrm{HD} / \mathrm{SD} /$ $\mathrm{HD}, \mathrm{n}=18$ ), EE6M (HD, $\mathrm{n}=27$; HD/SD, $\mathrm{n}=11$; HD/SD/ $\mathrm{HD}, \mathrm{n}=11$ ), IE18M (HD, $\mathrm{n}=19 ; \mathrm{HD} / \mathrm{SD}, \mathrm{n}=11 ; \mathrm{HD} / \mathrm{SD} /$ $\mathrm{HD}, \mathrm{n}=12)$, and EE18M (HD, $\mathrm{n}=18 ; \mathrm{HD} / \mathrm{SD}, \mathrm{n}=25$; $\mathrm{HD} / \mathrm{SD} / \mathrm{HD}, \mathrm{n}=27)$. HD groups were fed a continuous pellet diet; HD/SD regimes for 6 or 18 months followed an alternating pellet and powder diet every 3 or 9 months, respectively; and HD/SD/HD regimes for 6 or 18 months followed sequences of pellet, powder, and pellet food every 2 or 6 months, respectively (Figure 3). All animals were albino Swiss female mice.

\section{Behavioural tests}

At corresponding time points (6 or 18 months), all groups were trained in the water maze paradigm [9], adapted for mouse dimensions. The circular pool and

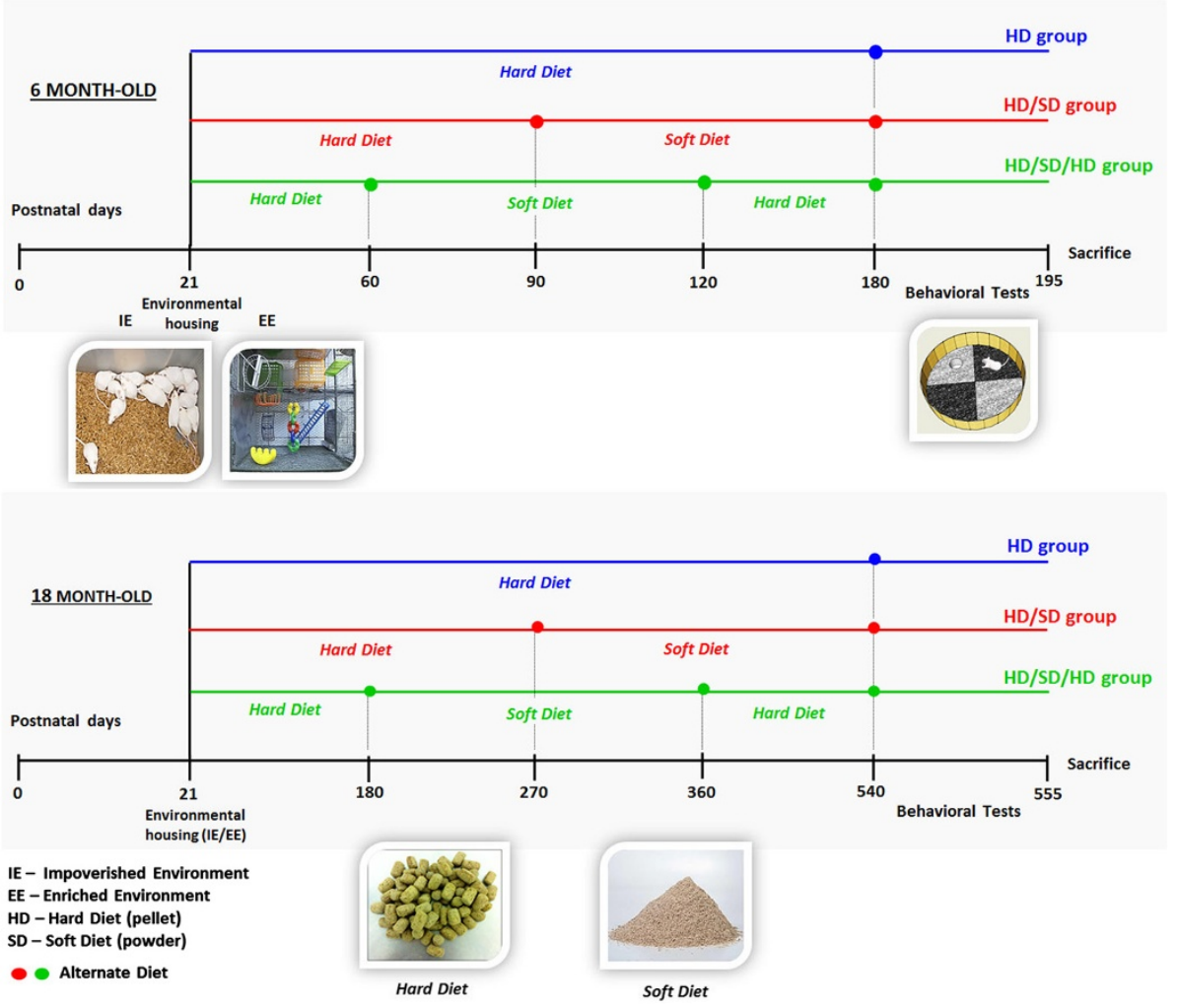

Figure 3 Experimental timeline. Female albino Swiss mice were housed either in impoverished or enriched environments (middle panel left) from postnatal days 21 until 180 ( 6 months old; $6 \mathrm{M}$ ) or 540 (18 months old; 18M), under one of the following diet regimes: HD groups correspond to continuous pellet diets; HD/SD regimes for 6 or 18 months correspond to alternating pellet and powder diet every 3 or 9 months, respectively; HD/SD/HD regimes for 6 or 18 months correspond to sequences of pellet, powder, and pellet food every 2 or 6 months, respectively. All 6M and 18M animals were submitted to the Morris water maze (middle panel, right) between 180 and 195 and between 540 and 555 postnatal days, respectively. Bottom panel: pellet (hard diet) and powder (soft diet) food. Time is represented in days after birth and increases from left to right. 
platform were 101 and $13 \mathrm{~cm}$ in diameter, respectively; the platform was $1 \mathrm{~cm}$ below the water surface. To occlude the platform, the pool was filled with black water $\left(22 \pm 2^{\circ} \mathrm{C}\right)$ coloured with a non-toxic dye. The first day of water maze training was dedicated to adapting the animal to the aquatic labyrinth. In the remaining 5 days, animals were tested once per day in three trials. Three permanent external cues were used during all day tests, and luminance level in the pool was kept constant between $4-5 \mathrm{~cd} / \mathrm{m}^{2}$. The enter points in the pool, based on dividing this apparatus according to cardinal points and thus into four equal quadrants, were semi-randomized, and we systematically avoided repeating entry at the same point more than twice. In each trial, the animals were allowed three trials of $60 \mathrm{~s}$ each to find the hidden platform; trials were separated by intervals of $30 \mathrm{~s}$, and the task was considered complete when they found and remained on the platform for $10 \mathrm{~s}$.

Any-Maze ${ }^{\oplus}$ tracking software was systematically used to precisely record the position of the mouse throughout the test. From this detailed positional information, we estimated for each animal a daily average value of escape latencies, travelled distances (path length), average swim speed, and time spent in the quadrant opposite to the hidden platform. The learning rate for the water maze was assessed by the ratio between escape latencies to find the platform on the first and subsequent test days (days 2-5) using the following equation: $\mathrm{C}=\left(\mathrm{L}_{1}-\mathrm{L}_{\mathrm{N}}\right)$ / $\left(\mathrm{L}_{1}+\mathrm{L}_{\mathrm{N}}\right)$, where $\mathrm{C}$ is a contrast index to express the learning rate and $\mathrm{L}_{1}$ and $\mathrm{L}_{\mathrm{N}}$ are the escape latencies to find the platform on the first and the subsequent test days, respectively. This equation was systematically applied every training day using the escape latency mean value of the daily three trials of each animal. Thus, four values of contrasts were obtained for each animal $\left(\mathrm{L}_{1} / \mathrm{L}_{2}\right.$, $\mathrm{L}_{1} / \mathrm{L}_{3}, \mathrm{~L}_{1} / \mathrm{L}_{4}$, and $\left.\mathrm{L}_{1} / \mathrm{L}_{5}\right)$, and a learning rate curve for five training days could be plotted for each animal. To express the learning rate in percentage values for each day, we selected from all experimental groups, independent of the diet regimen, age, or environment, the higher contrast value for each day and estimated the remaining contrast values as follows: $\mathrm{C}(\%)=\left[\left(\mathrm{L}_{1}-\mathrm{L}_{\mathrm{N}}\right) /\left(\mathrm{L}_{1}+\mathrm{L}_{\mathrm{N}}\right)\right]$ * $100 / C_{\max }$, where $C_{\max }$ corresponds to the best performance on that day in comparison with the first day and $\mathrm{L}_{1}$ and $\mathrm{L}_{\mathrm{N}}$ correspond to the escape latency in the first and subsequent days, respectively. Because the fourth training day showed the highest number of animals with a learning rate equal to or above $60 \%$ in all experimental groups, we selected this training day for comparative analysis between groups. To this end, we chose the five best performances of each experimental group from that day, considering that these five best specimens showed consistent learning $(\mathrm{C}(\%)>0$, at the fourth training day and on at least two more test days, or $\mathrm{C}(\%)>0$, at training days 4 and 5 ) and applied threeway ANOVA, followed by Tukey post-tests, with differences between groups accepted as significant at a 95\% confidence level ( $\mathrm{p}<0.05$ ). The contrast index has been previously applied to water maze results [51,52] to normalize the learning curve to each individual's performance, thus accounting for the variation in performances among individuals.

\section{Competing interests}

The authors declare that they have no competing interests.

\section{Authors' contributions}

FCCSM, MNFA, APGF, ACF, DJS, TGB, RPS, CWPD, and MCKS conceived the study, participated in the experimental design, and drafted the manuscript. FCCSM, MNFA, APGF, ACF, DJS, TGB, RPS, CWPD, and MCKS performed the experiments and analysed and interpreted the data. FCCSM, JBT, PFCV, VHP, EMLSR, CWPD, and MCKS participated in the data analysis, were involved in drafting the manuscript, and made important intellectual contributions. All authors read and approved the final manuscript.

\section{Acknowledgments}

This project was supported by research funds from the Brazilian government. MCKS was supported by grants from the Brazilian Research Council CNPq (grant numbers 475677/2008-0 and 470077/2012-3) and the Fundação de Amparo à Pesquisa do Estado do Pará (FAPESPA, grant number 136/08). Research funds from the Fundação de Amparo e Desenvolvimento da Pesquisa (FADESP) and the Pró-Reitoria de Pesquisa e Pós-Graduação (PROPESP/UFPA) covered proofreading, editing, and publication fees.

\section{Author details}

${ }^{1}$ Universidade Federal do Pará/UFPA, Instituto de Ciências Biológicas, Laboratório de Investigações em Neurodegeneração e Infecção, Hospital Universitário João de Barros Barreto, Rua dos Mundurucus, 4487 - Guamá Belém, Pará, Brasil. ${ }^{2}$ Instituto Evandro Chagas/ IEC, Departamento de Arbovirologia e Febres Hemorrágicas, Ananindeua, Pará, Brasil. ${ }^{3}$ Southampton Neuroscience Group, School of Biological Sciences, University of Southampton, Southhampton, UK. ${ }^{4}$ Universidade Federal do Pará/UFPA, Instituto de Ciências Exatas e Naturais, Laboratório de Sistema de Informação e Georrefrenciamento, Pará, Brasil.

Received: 13 May 2013 Accepted: 20 June 2013

Published: 28 June 2013

\section{References}

1. Miura H, Yamasaki K, Kariyasu M, Miura K, Sumi Y: Relationship between cognitive function and mastication in elderly females. J Oral Rehabil 2003, 30(8):808-811.

2. Weijenberg RA, Scherder EJ, Lobbezoo F: Mastication for the mind-the relationship between mastication and cognition in ageing and dementia. Neurosci Biobehav Rev 2011, 35(3):483-497.

3. Volkers KM, Scherder EJ: Impoverished environment, cognition, aging and dementia. Rev Neurosci 2011, 22(3):259-266.

4. Netz $Y$, Jacob T: Exercise and the psychological state of institutionalized elderly: a review. Percept Mot Skills 1994, 79(3 Pt 1):1107-1118.

5. Dorner T, Kranz A, Zettl-Wiedner K, Ludwig C, Rieder A, Gisinger C: The effect of structured strength and balance training on cognitive function in frail, cognitive impaired elderly long-term care residents. Aging Clin Exp Res 2007, 19(5):400-405.

6. Rolland Y, Pillard F, Klapouszczak A, Reynish E, Thomas D, Andrieu S, Riviere $D$, Vellas B: Exercise program for nursing home residents with Alzheimer's disease: a 1-year randomized, controlled trial. J Am Geriatr Soc 2007, 55(2):158-165.

7. Diniz DG, Foro CA, Reqo CM, Gloria DA, de Oliveira FR, Paes JM, de Sousa AA, Takuhashi TP, Trindade LS, Turiel MC, et al: Environmental impoverishment and aging alter object recognition, spatial learning, and dentate gyrus astrocytes. Eur J Neurosci 2010, 32(3):509-519.

8. Winocur G: Environmental influences on cognitive decline in aged rats. Neurobiol Aging 1998, 19(6):589-597. 
9. Morris R: Developments of a water-maze procedure for studying spatial learning in the rat. J Neurosci Methods 1984, 11(1):47-60.

10. Morris RG, Garrud P, Rawlins JN, O'Keefe J: Place navigation impaired in rats with hippocampal lesions. Nature 1982, 297(5868):681-683.

11. Moser E, Moser MB, Andersen P: Spatial learning impairment parallels the magnitude of dorsal hippocampal lesions, but is hardly present following ventral lesions. J Neurosci 1993, 13(9):3916-3925.

12. Sharma S, Rakoczy S, Brown-Borg H: Assessment of spatial memory in mice. Life Sci 2010, 87(17-18):521-536.

13. Ono Y, Yamamoto T, Kubo KY, Onozuka M: Occlusion and brain function: mastication as a prevention of cognitive dysfunction. $J$ Oral Rehabil 2010, 37(8):624-640.

14. Wu B, Plassman BL, Crout RJ, Liang J: Cognitive function and oral health among community-dwelling older adults. J Gerontol A Biol Sci Med Sci 2008, 63(5):495-500.

15. Winter C, Kampik NB, Vedovelli L, Rothenberger F, Paunescu TG, Stehberger $P A$, Brown $D$, John $H$, Wagner $C A$ : Aldosterone stimulates vacuolar $H$ (+)-ATPase activity in renal acid-secretory intercalated cells mainly via a protein kinase C-dependent pathway. Am J Physiol Cell Physiol 2011, 301(5):C1251-1261.

16. Simonato M, Baritussio A, Ori C, Vedovelli L, Rossi S, Dalla Massara L, Rizzi S, Carnielli VP, Cogo PE: Disaturated-phosphatidylcholine and surfactant protein-B turnover in human acute lung injury and in control patients. Respir Res 2011, 12:36.

17. Kubo KY, Yamada Y, linuma M, Iwaku F, Tamura Y, Watanabe K, Nakamura $\mathrm{H}$, Onozuka M: Occlusal disharmony induces spatial memory impairment and hippocampal neuron degeneration via stress in SAMP8 mice. Neurosci Lett 2007, 414(2):188-191.

18. Onozuka M, Watanabe K, Mirbod SM, Ozono S, Nishiyama K, Karasawa N, Nagatsu I: Reduced mastication stimulates impairment of spatial memory and degeneration of hippocampal neurons in aged SAMP8 mice. Brain Res 1999, 826(1):148-153.

19. Watanabe K, Ozono S, Nishiyama K, Saito S, Tonosaki K, Fujita M, Onozuka M: The molarless condition in aged SAMP8 mice attenuates hippocampal Fos induction linked to water maze performance. Behav Brain Res 2002, 128(1):19-25.

20. Yamazaki K, Wakabayashi N, Kobayashi T, Suzuki T: Effect of tooth loss on spatial memory and trkB-mRNA levels in rats. Hippocampus 2008, 18(6):542-547

21. de Almeida MN, Mendes FC, Felicio AP, Falsoni M, de Andrade ML, BentoTorres Neto J, Vasconcelos PF, Perry VH, Picanco-Diniz CW, Sosthenes MC: Spatial memory decline after masticatory deprivation and aging is associated with altered laminar distribution of CA1 astrocytes. BMC Neurosci 2012, 13(1):23.

22. Harburger LL, Lambert TJ, Frick KM: Age-dependent effects of environmental enrichment on spatial reference memory in male mice. Behav Brain Res 2007, 185(1):43-48.

23. Bennett JC, McRae PA, Levy LJ, Frick KM: Long-term continuous, but not daily, environmental enrichment reduces spatial memory decline in aged male mice. Neurobiol Learn Mem 2006, 85(2):139-152.

24. Frick KM, Fernandez SM: Enrichment enhances spatial memory and increases synaptophysin levels in aged female mice. Neurobiol Aging 2003, 24(4):615-626.

25. Frick KM, Stearns NA, Pan JY, Berger-Sweeney J: Effects of environmental enrichment on spatial memory and neurochemistry in middle-aged mice. Learn Mem 2003, 10(3):187-198

26. Speisman RB, Kumar A, Rani A, Pastoriza JM, Severance JE, Foster TC, Ormerod BK: Environmental enrichment restores neurogenesis and rapid acquisition in aged rats. Neurobiol Aging 2013, 34(1):263-274.

27. Segovia G, Yagüe AG, García-Verdugo JM, Mora F: Environmental enrichment promotes neurogenesis and changes the extracellular concentrations of glutamate and GABA in the hippocampus of aged rats. Brain Res Bull 2006, 70(1):8-14.

28. Qiu X, Huang CX, Lu W, Yang S, Li C, Shi XY, Chen L, Xiu Y, Yang JQ, Tang Y: Effects of a 4 month enriched environment on the hippocampus and the myelinated fibers in the hippocampus of middle-aged rats. Brain Res 2012, 1465:26-33.

29. Obiang P, Maubert E, Bardou I, Nicole O, Launay S, Bezin L, Vivien D, Agin V: Enriched housing reverses age-associated impairment of cognitive functions and tPA-dependent maturation of BDNF. Neurobiol Learn Mem 2011, 96(2):121-129.
30. Oliveira T: Efeitos da Estimulação Multissensorial e Cognitiva sobre o Declínio Cognitivo Senil agravado pelo Ambiente Empobrecido das Instituições de Longa Permanência. Instituto de Ciências Biológicas, Belém Pará - Brazil: Universidade Federal do Pará; 2012.

31. Onozuka M, Watanabe K, Fujita M, Tonosaki K, Saito S: Evidence for involvement of glucocorticoid response in the hippocampal changes in aged molarless SAMP8 mice. Behav Brain Res 2002, 131(1-2):125-129.

32. Onozuka M, Watanabe K, Nagasaki S, Jiang Y, Ozono S, Nishiyama K, Kawase T, Karasawa N, Nagatsu I: Impairment of spatial memory and changes in astroglial responsiveness following loss of molar teeth in aged SAMP8 mice. Behav Brain Res 2000, 108(2):145-155.

33. Kubo KY, Iwaku F, Watanabe K, Fujita M, Onozuka M: Molarless-induced changes of spines in hippocampal region of SAMP8 mice. Brain Res 2005, 1057(1-2):191-195.

34. Watanabe K, Tonosaki K, Kawase T, Karasawa N, Nagatsu I, Fujita M, Onozuka M: Evidence for involvement of dysfunctional teeth in the senile process in the hippocampus of SAMP8 mice. Exp Gerontol 2001, 36(2):283-295

35. Tsutsui K, Kaku M, Motokawa M, Tohma Y, Kawata T, Fujita T, Kohno S, Ohtani J, Tenjoh K, Nakano M, et al: Influences of reduced masticatory sensory input from soft-diet feeding upon spatial memory/learning ability in mice. Biomed Res 2007, 28(1):1-7.

36. Frotade Almeida M, Mendes F, Felício A, Falsoni M, Andrade M, BentoTorres J, Vasconcelos P, Perry V, Picanço-Diniz C, Sosthenes M: Spatial memory decline after masticatory deprivation and aging is associated with altered laminar distribution of CA1 astrocytes: behavioral and stereological analysis. BMC Neuroscience 2012, 13:23.

37. Kushida S, Kimoto K, Hori N, Toyoda M, Karasawa N, Yamamoto T, Kojo A, Onozuka M: Soft-diet feeding decreases dopamine release and impairs aversion learning in Alzheimer model rats. Neurosci Lett 2008, 439(2):208-211.

38. Kato T, Usami T, Noda Y, Hasegawa M, Ueda M, Nabeshima T: The effect of the loss of molar teeth on spatial memory and acetylcholine release from the parietal cortex in aged rats. Behav Brain Res 1997, 83(1-2):239-242.

39. Yamamoto T, Hirayama A: Effects of soft-diet feeding on synaptic density in the hippocampus and parietal cortex of senescence-accelerated mice. Brain Res 2001, 902(2):255-263.

40. Kubo KY, Ichihashi Y, Kurata C, linuma M, Mori D, Katayama T, Miyake H, Fujiwara S, Tamura Y: Masticatory function and cognitive function. Okajimas Folia Anat Jpn 2010, 87(3):135-140.

41. Akazawa Y, Kitamura T, Fujihara Y, Yoshimura Y, Mitome M, Hasegawa T: Forced mastication increases survival of adult neural stem cells in the hippocampal dentate gyrus. Int J Mol Med 2013, 31(2):307-314.

42. Flood JF, Morley JE: Age-related changes in footshock avoidance acquisition and retention in senescence accelerated mouse (SAM). Neurobiol Aging 1993, 14(2):153-157.

43. Miyamoto I, Yoshida K, Tsuboi Y, lizuka T: Rehabilitation with dental prosthesis can increase cerebral regional blood volume. Clin Oral Implants Res 2005, 16(6):723-727.

44. Ohta A, Hirano T, Yagi H, Tanaka S, Hosokawa M, Takeda T: Behavioral characteristics of the SAM-P/8 strain in Sidman active avoidance task. Brain Res 1989, 498(1):195-198.

45. Yagi H, Katoh S, Akiguchi I, Takeda T: Age-related deterioration of ability of acquisition in memory and learning in senescence accelerated mouse: SAM-P/8 as an animal model of disturbances in recent memory. Brain Res 1988, 474(1):86-93.

46. Arakawa $Y$, Ichihashi $Y$, linuma M, Tamura $Y$, Iwaku F, Kubo KY: Durationdependent effects of the bite-raised condition on hippocampal function in SAMP8 mice. Okajimas Folia Anat Jpn 2007, 84(3):115-119.

47. Ichihashi Y, Arakawa Y, linuma M, Tamura Y, Kubo KY, Iwaku F, Sato Y, Onozuka M: Occlusal disharmony attenuates glucocorticoid negative feedback in aged SAMP8 mice. Neurosci Lett 2007, 427(2):71-76.

48. linuma M, Ichihashi Y, Hioki Y, Kurata C, Tamura Y, Kubo KY: Malocclusion induces chronic stress. Okajimas Folia Anat Jpn 2008, 85(1):35-42.

49. Kubo KY, Saitoh N, Kogaya Y, Iwaku F, Ichihashi Y, Arakawa Y, Kurata C, linuma $\mathrm{M}$, Tamura $Y$ : The bite-raised condition enhances the aging process in the dorsal and ventral hippocampus. Okajimas Folia Anat Jpn 2008, 85(2):43-48.

50. Budtz-Jørgensen E: Occlusal dysfunction and stress. An experimental study in macaque monkeys. J Oral Rehabil 1981, 8(1):1-9. 
51. Torres JB, Assuncao J, Farias JA, Kahwage R, Lins N, Passos A, Quintairos A, Trevia N, Diniz CW: NADPH-diaphorase histochemical changes in the hippocampus, cerebellum and striatum are correlated with different modalities of exercise and watermaze performances. Experimental Brain Research 2006, 175(2):292-304.

52. Diniz DG, Foro CAR, Rego CMD, Gloria DA, de Oliveira FRR, Paes JMP, de Sousa AA, Tokuhashi TP, Trindade LS, Turiel MCP, et al: Environmental impoverishment and aging alter object recognition, spatial learning, and dentate gyrus astrocytes. European Journal of Neuroscience 2010, 32(3):509-519.

doi:10.1186/1471-2202-14-63

Cite this article as: Mendes et al.: Enriched environment and masticatory activity rehabilitation recover spatial memory decline in aged mice. $B M C$ Neuroscience 2013 14:63.

\section{Submit your next manuscript to BioMed Central and take full advantage of:}

- Convenient online submission

- Thorough peer review

- No space constraints or color figure charges

- Immediate publication on acceptance

- Inclusion in PubMed, CAS, Scopus and Google Scholar

- Research which is freely available for redistribution 